\title{
Synthesis and characterization of oxytetracycline imprinted magnetic polymer for application in food
}

\author{
Sneha Aggarwal ${ }^{1} \cdot$ Yudhishthir Singh Rajput $^{1} \cdot$ Gulab Singh $^{1} \cdot$ Rajan Sharma $^{2}$
}

Received: 18 December 2014/ Accepted: 11 March 2015/Published online: 24 March 2015

(C) The Author(s) 2015. This article is published with open access at Springerlink.com

\begin{abstract}
Magnetic imprinted polymer was prepared by polymerization of methacrylate and ethyleneglycoldimethacrylate in the presence of oxytetracycline on the surface of iron magnetite. Selectivity of prepared polymer was calculated from ratio of partition coefficient of oxytetracycline for imprinted and non- imprinted polymer in water, acetonitrile, methanol and at different $\mathrm{pH}$ in aqueous buffer. $\mathrm{pH}$ of solvent exhibited pronounced effect on selectivity. Selectivity at $\mathrm{pH} 7.0,6.0$ and 5.0 was 36.0, 2.25 and 1.61 fold higher than at $\mathrm{pH}$ 4.0. Imprinted polymer was not selective for oxytetracycline in methanol. However, selectivity in water and acetonitrile was 19.42 and 2.86 , respectively. Oxytetracycline did bind to imprinted polymer in water or aqueous buffer $(\mathrm{pH} 7.0)$ and could be eluted with methanol. Prepared polymer extracted 75-80\% oxytetracycline from water, honey and egg white.
\end{abstract}

Keywords Iron nanoparticle $\cdot$ Oxytetracycline imprinted polymer $\cdot$ Selectivity $\cdot$ Food

\section{Introduction}

The widespread use of antibiotics in dairy cattle, poultry and bee keeping leads to presence of antibiotic residues in food chain. To prevent any harmful health effects on consumers, FAO, WHO and European Union have

Yudhishthir Singh Rajput ys_rajput@rediffmail.com

1 Animal Biochemistry Division, National Dairy Research Institute, Karnal 132001, India

2 Dairy Chemistry Division, National Dairy Research Institute, Karnal 132001, India established the maximum residual limits for veterinary drugs (Council Regulation 2377/90/EEC). Oxytetracycline (OTC) is a broad spectrum antibiotic against Gram-positive and Gram-negative bacteria. It is used for the treatment of bacterial brood disease and is the most commonly applied tetracycline group of antibiotics to food producing animals. OTC also finds application in human therapy, apiculture and fruit crop production (Niazi et al. 2008). The presence of OTC residue in foods may constitute a variety of public health hazards including toxicological, microbiological, immunological and pharmacological hazards (Navrátilová et al. 2009). Frequent use of antibiotic impacts on emergence of antimicrobial resistance creates disorder in intestinal flora and may lead to possible occurrence of allergic reactions (Honkanen-Buzalski and Reybroeck 1997; Roberts 1997; Cerniglia and Kotarski 2005). Food analysis requires extensive sample preparation prior to its instrumental analysis (Ridgway et al. 2007). Classical sample preparation technique, which involves repeated sample extraction with solvent under shaking, followed by centrifugation, results in low extraction yield (Yan et al. 2007). Some high extraction yielding techniques such as pressurized liquid extraction (Haglund et al. 2007; Soler et al. 2007), supercritical fluid extraction (Jiménez-Carmona and Luque de Castro 1998; Rodil et al. 2005) microwave-assisted extraction (Cheng et al. 2007; You et al. 2007) and ultrasonic-assisted extraction (Ruiz-Jiménez et al. 2004; Rezić et al. 2005)] have also been applied for food analysis. However, prepared sample is not suitable for direct instrument analysis and requires one or more prior purification steps (Heems et al. 1998; Buldini et al. 2002; Paleologos and Kontominas 2004; Hamscher et al. 2005; Kuhnle et al. 2007). Extraction protocol specific to analyte can lead to clean sample preparation. 
Molecular imprinting is a technique which creates stable synthetic polymers possessing tailor-made selective recognition sites, obtained using high amount of crosslinker in the presence of template molecule (Xie et al. 2003). Once polymerization is over, removal of template from polymer leaves specific cavities which can rebind template selectively on the basis of shape, size and functionality. Despite the advantages of molecular imprinting polymer such as stability at extreme of $\mathrm{pH}$ and temperature, ease of preparation, low cost and reusability, it requires column or pre-packed column and negative or positive pressure generating pump or centrifuge.

The magnetic polymer is prepared by encapsulating inorganic magnetic particles in organic polymers (Yao et al. 2008). On integration of magnetic separation technology with imprinted polymer, the resulting magnetic polymer will have magnetic properties and selective for template molecule. Magnetic separation technology makes separation of analyte easier and faster and also provides large surface to volume ratio. The present study reports synthesis and application of OTC-imprinted magnetic polymer.

\section{Materials and methods}

\section{Materials}

OTC-HCl, tetracycline, metacycline, chlortetracycline, cefquinome, gentamycin, methacrylic acid (MAA), ethylene glycol dimethacrylate (EGDMA), oleic acid, Iron(II) chloride $\left(\mathrm{FeCl}_{2} \cdot 4 \mathrm{H}_{2} \mathrm{O}\right)$, Iron (III) chloride $\left(\mathrm{FeCl}_{3} \cdot 6 \mathrm{H}_{2} \mathrm{O}\right)$, polyvinylpyrrilidone (PVP), azobisisobutyronitrile (AIBN) were purchased from Sigma Aldrich, USA. Methanol (HPLC grade), ethanol, acetic acid glacial and acetonitrile (HPLC grade) were procured from Hi-media, India.

\section{Food samples}

Honey was obtained from Dabar India, Ltd., and eggs were obtained from local market. These food samples were spiked with OTC stock solution $(100 \mu \mathrm{g} / \mathrm{mL})$ prepared in water.

\section{Preparation of magnetic molecular imprinted polymer}

Preparation of oleic acid coated $\mathrm{Fe}_{3} \mathrm{O}_{4}$ magnetite and EGDMA mix

The $\mathrm{Fe}_{3} \mathrm{O}_{4}$ magnetite was prepared by co-precipitation method as described by Chen and $\mathrm{Li}$ (2013). $1.98 \mathrm{~g}$ of $\mathrm{FeCl}_{2} \cdot 4 \mathrm{H}_{2} \mathrm{O}$ and $5.41 \mathrm{~g}$ of $\mathrm{FeCl}_{3} \cdot 6 \mathrm{H}_{2} \mathrm{O}$ were dissolved in
$100 \mathrm{~mL}$ of deaerated water. The mixture was stirred vigorously and purged with nitrogen gas while temperature was raised to $80{ }^{\circ} \mathrm{C}$. Then, $40 \mathrm{~mL}$ of sodium hydroxide solution $(2 \mathrm{~N})$ was added dropwise. After $1 \mathrm{~h}$, magnetic precipitates were separated with help of external magnet and washed several times with deaerated water. After washing, precipitates were dried at $60{ }^{\circ} \mathrm{C} .1 \mathrm{~g} \mathrm{Fe}_{3} \mathrm{O}_{4}$ magnetite (freshly prepared) and $1.0 \mathrm{~mL}$ oleic acid were mixed. Then, $3.77 \mathrm{~mL}$ EGDMA was added and mixed.

\section{Preassembly solution of monomer and OTC}

In separate beaker, $1.0 \mathrm{mmol}$ OTC and $344 \mu \mathrm{L}$ MAA were added to $10 \mathrm{~mL}$ deaerated water to allow interaction between MAA and OTC. The contents were mixed for 10 min.

\section{Pre-polymerization mix}

Iron magnetite-EGDMA mix and preassembly solution were mixed and sonicated for $30 \mathrm{~min}$.

\section{Polymerization reaction}

$0.4 \mathrm{~g}$ PVP was dissolved in $100 \mathrm{~mL} 80 \%$ ethanol at $60{ }^{\circ} \mathrm{C}$ and purged with nitrogen gas. Then, pre polymerization mix and $3 \mathrm{~mL}$ AIBN were added. Reaction was allowed to proceed at $60{ }^{\circ} \mathrm{C}$ for $24 \mathrm{~h}$ under continuous stirring at $300 \mathrm{rpm}$. Prepared polymer was separated with help of external magnet and washed several times with methanol: acetic acid $(8: 2 \mathrm{v} / \mathrm{v})$ mixture, till washings were free from OTC. The polymer was further washed three times with deaerated water and dried at $60{ }^{\circ} \mathrm{C}$.

Magnetic non-imprinted polymer (MNIP) was prepared similarly to that of magnetic molecular imprinted polymer (MMIP), except OTC was omitted from pre-assembly solution.

\section{Characterization}

MMIP was characterized by scanning electron microscope (SEM; Make: Carl Zeiss, Germany) and Fourier transform infrared spectrometry (FT-IR Sumazdu, IR affinity, Japan). The size of prepared iron nano particle and MMIP was determined with Zetasizer, (Malvern, USA).

\section{Selectivity of imprinted polymer}

Selectivity was calculated from ratios of partition coefficient of OTC in imprinted and non-imprinted polymer (Cai and Gupta 2004). Polymers (20 mg) were incubated with $2 \mathrm{~mL}$ OTC $(40 \mu \mathrm{g})$ prepared in different solvent for $24 \mathrm{~h}$ at $30{ }^{\circ} \mathrm{C}$. Unbound OTC and other studied antibiotics were 
assayed in supernatant by measuring absorbance at $325 \mathrm{~nm}$. Bound antibiotic was calculated by subtracting unbound antibiotic from total antibiotic added.

\section{Evaluation of MMIP performance in food matrix}

Two grams of honey or $2 \mathrm{~mL}$ of egg white or $2 \mathrm{~mL}$ of water was spiked with $200 \mu \mathrm{g}$ OTC and diluted with $20 \mathrm{~mL}$ water. Diluted sample or water was mixed with $40 \mathrm{mg}$ imprinted or non-imprinted polymer. Then, polymer was ten times washed with $3 \mathrm{~mL}$ water and supernatant from each washing was collected. The bound OTC was eluted six times with $3 \mathrm{~mL}$ methanol.

The imprinted polymer was preconditioned with water before use. Preconditioning of polymer was achieved by vortexing polymer for $10 \mathrm{~min}$. Supernatant was then removed.

\section{Results and discussion}

Magnetic properties of imprinted polymer coated over the iron magnetite surface lead to easy separation of polymer after binding to target molecules. Therefore, such polymers have added advantage over non-magnetic imprinted polymers. Iron magnetite and polymers are core and coat of magnetic imprinted polymer, respectively. Polymer yield from $4 \mathrm{mmol}$ MAA and $20 \mathrm{mmol}$ EGDMA in the presence of $1 \mathrm{mmol}$ OTC was $4.2 \mathrm{~g}$. Imprinted polymer was brown in color while non-imprinted polymer was black. OTC imprinted particles were of $220 \mathrm{~nm}$ in size and appear porous (Fig. 1). Polymer exhibited peak at $540 \mathrm{~cm}^{-1}$ (characteristic of $\mathrm{Fe}-\mathrm{O}$ bond stretching), $1370 \mathrm{~cm}^{-1}(\mathrm{C}-\mathrm{H}$

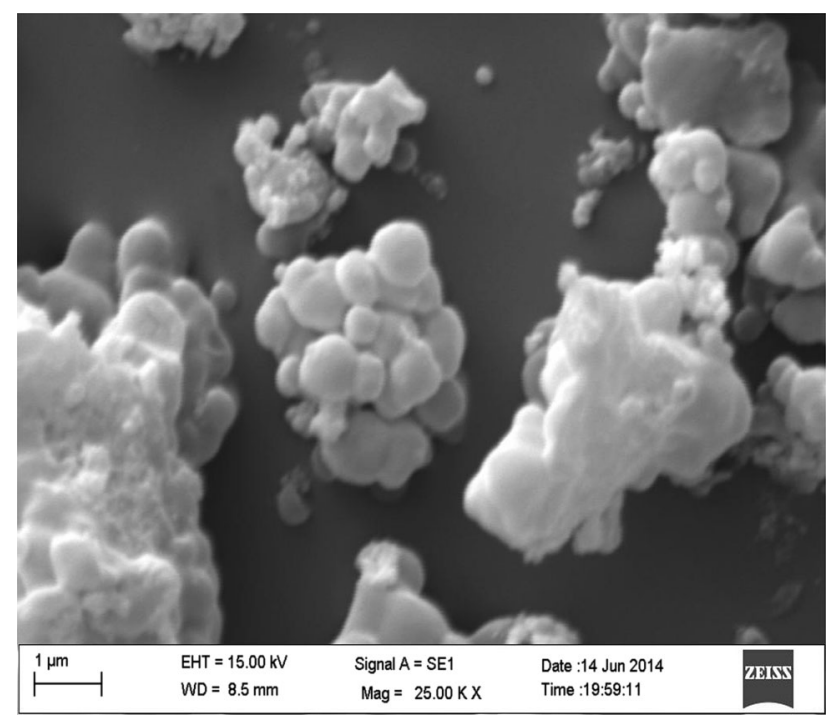

Fig. 1 SEM image of magnetic molecular imprinted polymer bond vibration), $1450 \mathrm{~cm}^{-1}(\mathrm{C}-\mathrm{H}$ bond stretching) and $1724 \mathrm{~cm}^{-1}$ (carbonyl bond stretching) in FTIR (Chen et al. 2010; Hong et al. 2010) (Fig. 2). There was no difference in FTIR spectra of OTC-imprinted and non-imprinted polymer.

\section{Effect of solvents on binding of oxytetracycline}

The binding efficiency of OTC imprinted polymer was dependent on solvent (Table 1). Binding efficiency of magnetic imprinted polymer was highest in water $(82 \%)$, followed by acetonitrile (30\%) and methanol (11\%). This shows that binding in polar solvents was considerably high in comparison to non-polar solvent and interaction between OTC and polymer appears largely hydrophobic in nature. Binding in acetonitrile shows that there is also possibility of involvement of hydrogen bond for interaction between OTC and magnetic imprinted polymer. Selectivity value reflects preferential binding of target to imprinted polymer over non-imprinted polymer. Solvent can influence noncovalent interaction between OTC and polymer and thereby influence selectivity. Selectivity of magnetic molecular imprinted polymer was solvent-dependent and was highest in water followed by acetonitrile and abolished in methanol. The results suggest involvement of hydrophobic interaction and hydrogen bond.

\section{Effect of $\mathrm{pH}$ on binding of oxytetracycline to magnetic imprinted polymer}

Binding efficiency of imprinted and non-imprinted polymers for OTC was dependent on $\mathrm{pH}$ (Table 1). Striking difference was observed in binding of OTC to non-imprinted polymer at different $\mathrm{pH}$. As $\mathrm{pH}$ decreased, binding of OTC to non-imprinted polymer increased. Binding of OTC to imprinted polymer was highest at $\mathrm{pH}$ 7.0. The difference in binding of OTC to both imprinted and nonimprinted polymer at different $\mathrm{pH}$ resulted from dependence of selectivity on $\mathrm{pH}$. The selectivity was highest at $\mathrm{pH} 7.0$, whereas at $\mathrm{pH} 4.0$ there was no selectivity. Nonimprinted polymer also binds to OTC in $\mathrm{pH}$-dependent way. Dissociation of carboxylic group (pKa 5.5) in poly methacrylic acid (Zhang and Nicholas 2000) and of three hydroxyl groups (pKa values being 3.32, 7.78 and 9.58) present in OTC (Sassman and Lee 2005; O'Connor and Aga 2007) is dependent on pH. When both carboxylic and hydroxyl groups exist in dissociated form, hydrogen bond formation between polymer and OTC will be discouraged. At $\mathrm{pH}$ 7.0, hydrogen bond formation will be least favorable amongst the studied $\mathrm{pH}$ ranges $(7.0,6.0,5.0$ and 4.0). The significant binding in the $\mathrm{pH}$ range of 4-6 resulted from hydrogen bond between surface carboxylic group of polymer and OTC. Imprinted polymer still binds with OTC 
Fig. 2 FTIR spectrum of magnetic OTC imprinted Polymer

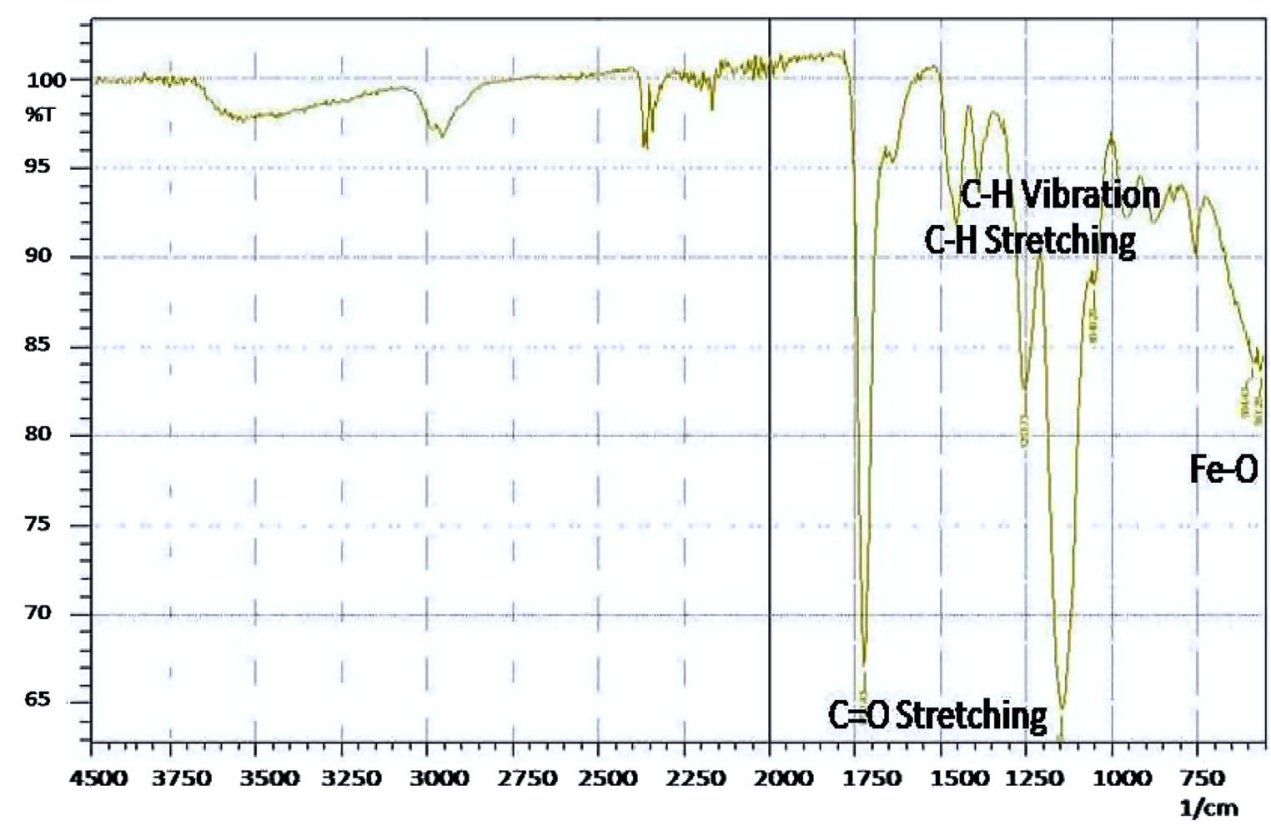

Table 1 Effect of solvent on binding, partition coefficient and selectivity of oxytetracycline magnetically imprinted polymer

\begin{tabular}{|c|c|c|c|c|}
\hline Solvent & Polymer & Percentage bound & Partition coefficient & Selectivity \\
\hline \multirow[t]{2}{*}{ Water } & Imprinted & 82 & 455.55 & \multirow[t]{2}{*}{19.42} \\
\hline & Non-imprinted & 19 & 23.45 & \\
\hline \multirow[t]{2}{*}{ Methanol } & Imprinted & 11 & 12.35 & \multirow[t]{2}{*}{0.98} \\
\hline & Non-imprinted & 12 & 13.63 & \\
\hline \multirow[t]{2}{*}{ Acetonitrile } & Imprinted & 30 & 42.85 & \multirow[t]{2}{*}{2.86} \\
\hline & Non-imprinted & 13 & 14.94 & \\
\hline \multirow[t]{2}{*}{$20 \mathrm{mM}$ acetate buffer ( $\mathrm{pH} 4.0$ ) } & Imprinted & 70 & 233.33 & \multirow[t]{2}{*}{1} \\
\hline & Non-imprinted & 70 & 233.33 & \\
\hline \multirow[t]{2}{*}{$20 \mathrm{mM}$ acetate buffer (pH 5.0) } & Imprinted & 69 & 222.58 & \multirow[t]{2}{*}{1.61} \\
\hline & Non-imprinted & 58 & 138.09 & \\
\hline \multirow[t]{2}{*}{$20 \mathrm{mM}$ phosphate buffer ( $\mathrm{pH} 6.0$ ) } & Imprinted & 63 & 170.27 & \multirow[t]{2}{*}{2.25} \\
\hline & Non-imprinted & 43 & 75.43 & \\
\hline \multirow[t]{2}{*}{$20 \mathrm{mM}$ phosphate buffer ( $\mathrm{pH}$ 7.0) } & Imprinted & 90 & 900 & \multirow[t]{2}{*}{36} \\
\hline & Non-imprinted & 20 & 25 & \\
\hline
\end{tabular}

at $\mathrm{pH} 7.0$ in a significant way, primarily through hydrophobic interaction.

\section{Effect of time duration on binding of oxytetracycline to imprinted polymer}

The effect of time duration on binding of oxytetracycline to imprinted polymer was studied. Polymer was immersed in OTC solution prepared in $20 \mathrm{mM}$ phosphate buffer ( $\mathrm{pH} 7.0)$ at $25^{\circ} \mathrm{C}$ up to $40 \mathrm{~h}$ (Fig. 3). Binding of OTC to imprinted polymer increases with increase in time duration up to $24 \mathrm{~h}$ and then remains constant. This shows that maximum binding sites were occupied by OTC in $24 \mathrm{~h}$.

\section{Cross-reactivity of oxytetracycline imprinted polymer}

Forty microgram each of antibiotics was incubated with $20 \mathrm{mg}$ polymer in $2 \mathrm{~mL}, 20 \mathrm{mM}$ phosphate buffer ( $\mathrm{pH} 7.0)$ for $24 \mathrm{~h}$ at $25^{\circ} \mathrm{C}$. Bound antibiotic was calculated by subtracting unbound antibiotic from total antibiotic. As against $90 \%$ binding of OTC to imprinted polymer, binding of metacycline, chlortetracycline, tetracycline, cefquinome and gentamycine was 10, 15, 20, 20 and $12 \%$, respectively (Fig. 4). It may be also noted that only 10-20\% of antibiotic did bind to non-imprinted polymer. Prepared MMIP was more selective for OTC as other studied antibiotics showed low cross-reactivity 


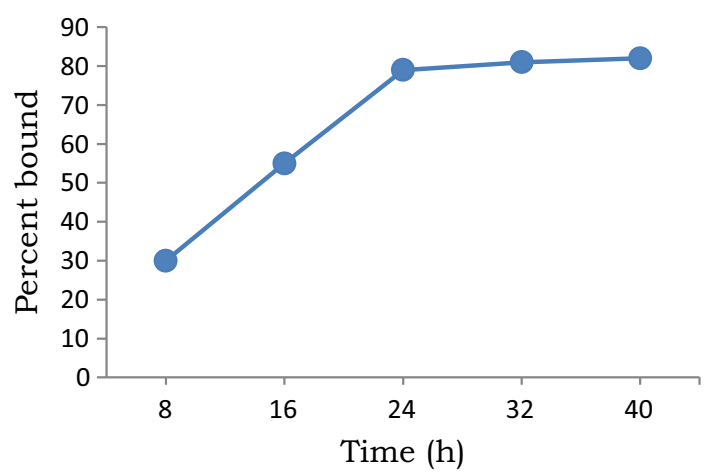

Fig. 3 Effect of time duration on binding of OTC to imprinted polymer. $40 \mu \mathrm{g}$ of antibiotic was incubated with $20 \mathrm{mg}$ polymer in $2 \mathrm{~mL}$ of $20 \mathrm{mM}$ phosphate buffer $(\mathrm{pH} 7)$ at $30^{\circ} \mathrm{C}$

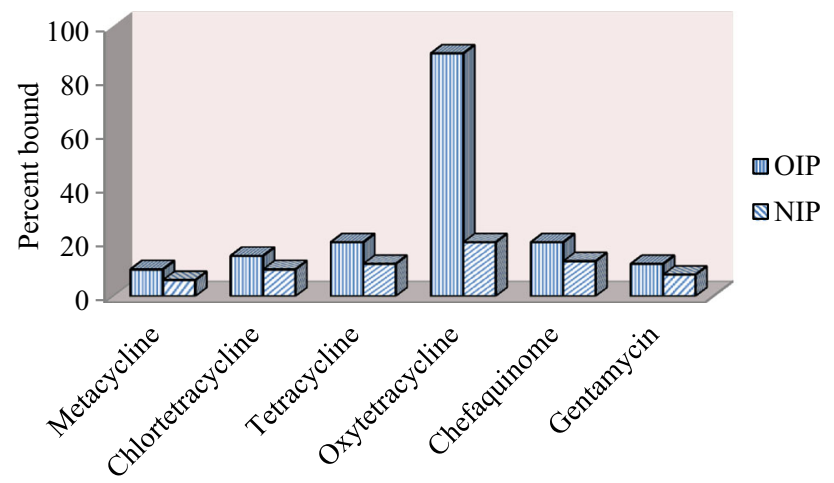

Fig. 4 Binding of different antibiotics to OTC-imprinted polymer (OIP). $40 \mu \mathrm{g}$ of antibiotic was incubated with $20 \mathrm{mg}$ polymer in $2 \mathrm{~mL}$ of $20 \mathrm{mM}$ phosphate buffer $(\mathrm{pH} \mathrm{7})$ for $24 \mathrm{~h}$ at $30{ }^{\circ} \mathrm{C}$. NIP non-imprinted polymer

\section{Application of MMIP for recovery of OTC from water, honey and egg white}

OTC-imprinted polymer was employed for extraction of OTC from water, honey and egg white. Recovery of OTC from water, honey and egg white was 80,76 and $75 \%$, respectively. Caro et al. (2005) prepared OTC-imprinted polymer and utilized it as solid-phase extractant for extraction of OTC and achieved $70-80 \%$ recovery. The nonimprinted polymer does not show specific binding with OTC from water, honey and egg white and hence does not help in recovery of OTC. While imprinted polymer showed specific binding with OTC and was also able to recover OTC from water, honey and egg white in range of 75-80 \%.

\section{Conclusion}

In this paper, non covalent molecular imprinting protocol was used to prepare OTC-imprinted magnetic polymer. The selectivity of polymer for OTC was dependent on solvents used for binding. The prepared magnetic imprinted polymer extracted 75-80 \% OTC from food matrix. Magnetic imprinted polymer provides an easy method for separation of polymer from food matrix or water.

Acknowledgments The authors are thankful to the National Funds for Basic, Strategic and Frontier Application Research in Agriculture (NFBSFARA) for providing funds for research. Research fellowship awarded to Sneha Aggarwal during the research work from ICARNDRI is also acknowledged.

Open Access This article is distributed under the terms of the Creative Commons Attribution License which permits any use, distribution, and reproduction in any medium, provided the original author(s) and the source are credited.

\section{References}

Buldini PL, Ricci L, Sharma JL (2002) Recent applications of sample preparation techniques in food analysis. J Chromatogr A 975(1):47-70

Cai W, Gupta RB (2004) Molecular-imprinted polymers selective for tetracycline binding. Sep Purif Technol 35:215-221

Caro E, Marce RM, Cormack PAG, Sherrington DC, Borrull F (2005) Synthesis and application of an oxytetracycline imprinted polymer for the solid-phase extraction of tetracycline antibiotics. Anal Chim Acta 552:81-86

Cerniglia CE, Kotarski S (2005) Approaches in the safety evaluations of veterinary antimicrobial agents in food to determine the effects on the human intestinal microflora. J Vet Pharmacol Ther 28:3-20

Chen L, Li B (2013) Magnetic molecularly imprinted polymer extraction of chloramphenicol from honey. Food Chem 141(1):23-28

Chen BY, Pyla R, Kim TJ, Silva JL, Jung YS (2010) Antibiotic resistance in Listeria species isolated from catfish fillets and processing environment. Lett Appl Microbiol 50(6):626-632

Cheng J, Liu M, Zhang X, Ding L, Yu Y, Wang X, Jin H, Zhang H (2007) Determination of triazine herbicides in sheep liver by microwave-assisted extraction and high performance liquid chromatography. Anal Chim Acta 590(1):34-39

Haglund P, Sporring S, Wiberg K, Björklund E (2007) Shapeselective extraction of PCBs and dioxins from fish and fish oil using in-cell carbon fractionation pressurized liquid extraction. Anal Chem 79:2945-2951

Hamscher G, Priess B, Nau H, Panariti E (2005) Determination of colchicine residues in sheep serum and milk using highperformance liquid chromatography combined with electrospray ionization ion trap tandem mass spectrometry. Anal Chem 77(8):2421-2425

Heems D, Luck G, Fraudeau C, Verette E (1998) Fully automated per column derivatization, online dialysis and high performance liquid chromatographic analysis of amino acids in food beverages and feedstuff. J Chromatogr A 798:9-17

Hong CC, Chang PH, Lin CC, Hong CL (2010) A disposable microfluidic biochip with on-chip molecularly imprinted biosensors for optical detection of anesthetic propofol. Biosens Bioelectron 25(9):2058-2064

Honkanen-Buzalski T, Reybroeck W (1997) Antimicrobials. monograph on residues and contaminants in milk and milk products. IDF special issue 9701, International Dairy Federation, Brussel, pp 26-33 
Jiménez-Carmona MM, Luque de Castro MD (1998) Reverse micelle formation for acceleration of the supercritical fluid extraction of cholesterol from food samples. Anal Chem 70:2100-2103

Kuhnle GG, Dellaquila C, Low YL, Kussmaul M, Bingham SA (2007) Extraction and quantification of phytoestrogens in foods using automated solid-phase extraction and LC/MS/MS. Anal Chem 79(23):9234-9239

Navrátilová $\mathrm{P}$, Borkovcová I, Dračková M, Janštová B, Vorlova L (2009) Occurrence of tetracycline, chlortetracycline, and oxytetracycline residues in raw cow's milk. Czech J Food Sci 27(5):379-385

Niazi JH, Lee SJ, Kim YS, Gu MB (2008) ssDNA aptamers that selectively bind oxytetracycline. Bioorg Med Chem 16:1254-1261

O'Connor S, Aga DS (2007) Analysis of tetracycline antibiotics in soil: advances in extraction, clean-up, and quantification. Trends Anal Chem 26:456-464

Paleologos EK, Kontominas MG (2004) On-line solid-phase extraction with surfactant accelerated on-column derivatization and micellar liquid chromatographic separation as a tool for the determination of biogenic amines in various food substrates. Anal Chem 76(5):1289-1294

Rezić I, Horvat AJ, Babić S, Kastelan-Macan M (2005) Determination of pesticides in honey by ultrasonic solvent extraction and thin-layer chromatography. Ultrason Sonochem 12(6):477-481

Ridgway K, Lalljie SPD, Smith RM (2007) Sample preparation techniques for the determination of trace residues and contaminants in foods. J Chromatogr A 1153:36-53

Roberts MC (1997) Genetic mobility and distribution of tetracycline resistance determinants. In: Antibiotic resistance: origins, evolution, selection and spread. Wiley, Chichester (Ciba Found Symp 207), pp 206-222

Rodil R, Carro AM, Lorenzo RA, Cela Torrijos R (2005) Selective extraction of trace levels of polychlorinated and polybrominated contaminants by supercritical fluid-solid-phase microextraction and determination by gas chromatography/mass spectrometry.
Application to aquaculture fish feed and cultured marine species. Anal Chem 77:2259-2265

Ruiz-Jiménez J, Priego-Capote F, de Castro MD (2004) Identification and quantification of trans fatty acids in bakery products by gas chromatography-mass spectrometry after dynamic ultrasoundassisted extraction. J Chromatogr A 1045(1-2):203-210

Sassman SA, Lee LS (2005) Sorption of three tetracyclines by several soils: Assessing the role of $\mathrm{pH}$ and cation exchange. Environ Sci Technol 39:7452-7459

Soler C, Hamilton B, Furey A, James KJ, Manes J, Pico Y (2007) Liquid chromatography quadrupole time of flight mass spectrometry analysis of carbosulfan, carbofuran, 3-hydroxycarbofuran and other metabolites in food. Anal Chem 79:1492-1501

Xie J, Chen L, Li C, Xu X (2003) Selective extraction of functional components derived from herb in plasma by using a molecularly imprinted polymer based on 2,2-bis (hydroxymethyl) butanol trimethacrylate. J Chromatogr B-Anal Technol Biomed Life Sci 788(2):233-242

Yan H, Qiao F, Row KH (2007) Molecularly imprinted-matrix solidphase dispersion for selective extraction of five fluoroquinolones in eggs and tissue. Anal Chem 79:8242-8248

Yao N, Chen H, Lin H, Deng C, Zhang X (2008) Enrichment of peptides in serum by $\mathrm{C}(8)$-functionalized magnetic nanoparticles for direct matrix-assisted laser desorption/ionization timeof-flight mass spectrometry analysis. J Chromatogr A 1185(1):93-101

You J, Zhang H, Zhang H, Yu A, Xiao T, Wang Y, Song D (2007) Determination of triazines in infant nutrient cereal-based foods by pressurized microwave-assisted extraction coupled with highperformance liquid chromatography-mass spectrometry. J Chromatogr B Anal Technol Biomed Life Sci 856(1-2):278-284

Zhang J, Nicholas AP (2000) Synthesis and characterization of $\mathrm{pH}$ and temperature sensitive poly (methacrylic acid)/poly (Nisopropylacrylamide) interpenetrating polymeric networks. Macromolecules 33:102-107 